Corrigendum

\title{
Corrigendum to "Application of a New Method in Identifying the Sludge Deposits from Refineries and Gas Plants: A Case of Laboratory-Based Study"
}

\author{
Husin Sitepu (D), Rasha A. Al-Ghamdi, and Syed R. Zaidi \\ Research and Development Center, Saudi Aramco, Saudi Arabia \\ Correspondence should be addressed to Husin Sitepu; sitepuhx@aramco.com \\ Received 22 May 2018; Accepted 20 June 2018; Published 1 August 2018
}

Copyright (C) 2018 Husin Sitepu et al. This is an open access article distributed under the Creative Commons Attribution License, which permits unrestricted use, distribution, and reproduction in any medium, provided the original work is properly cited.

\begin{abstract}
In the article entitled "Application of a New Method in Identifying the Sludge Deposits from Refineries and Gas Plants: A Case of Laboratory-Based Study" [1], Rasha A. AlGhamdi was missing from the authors' list. Rasha A. AlGhamdi performed the separation of the inorganic materials part (non-hydrocarbon) from the hydrocarbon part for the complex sample such as sludge deposit collected from the NG line, where the methylene chloride was insoluble. Rasha A. Al-Ghamdi also conducted the materials characterization of hydrocarbon parts using both the thermal gravimetric analysis and gas chromatography mass spectrometry techniques. Additionally, Rasha A. Al-Ghamdi interpreted the results, e.g., type of hydrocarbon (i.e., hydrocarbon type was diesel with the C10-C27) and the amount of inorganic compound, water, and hydrocarbon content (3wt\% of inorganic compound, $25 \mathrm{wt} \%$ of water, and $72 \mathrm{wt} \%$ of hydrocarbon content). The corrected authors' list is shown above.
\end{abstract}

\section{References}

[1] H. Sitepu and S. R. Zaidi, "Application of a new method in identifying the sludge deposits from refineries and gas plants: a case of laboratory-based study," International Journal of Corrosion, Article ID 9047545, 7 pages, 2017. 


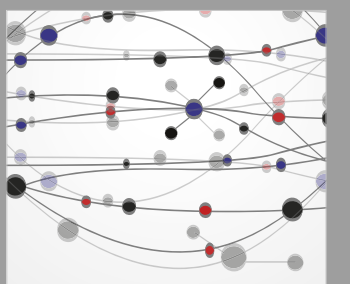

The Scientific World Journal
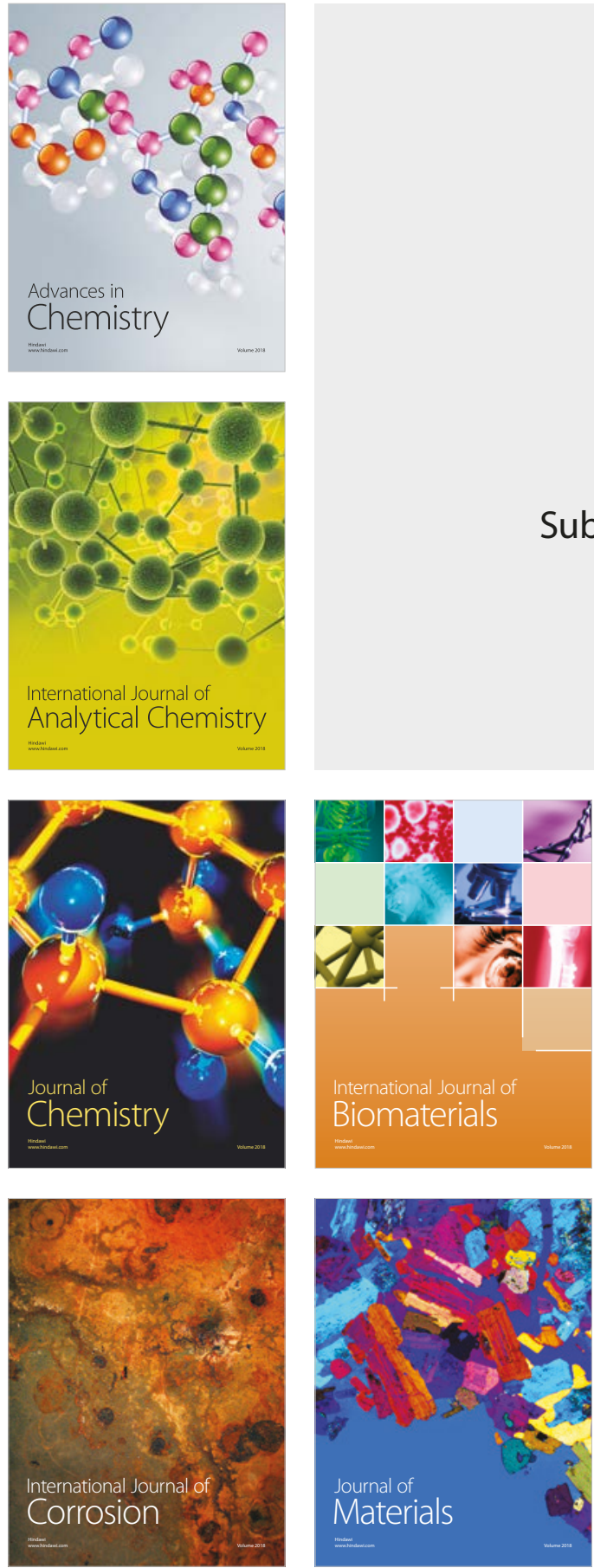

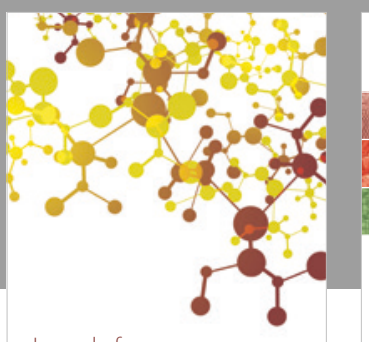

Journal of

Applied Chemistry
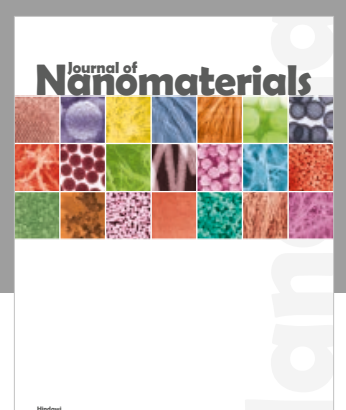

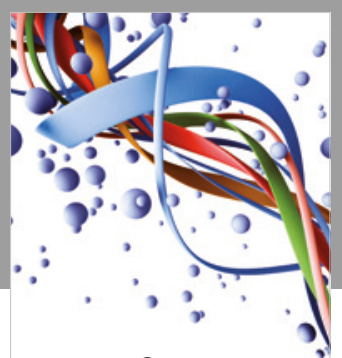

Scientifica

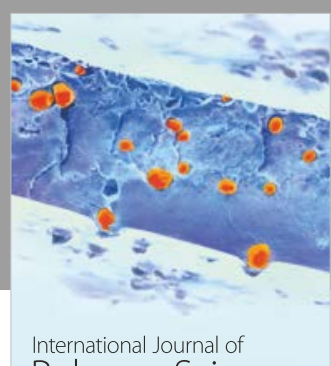

Polymer Science

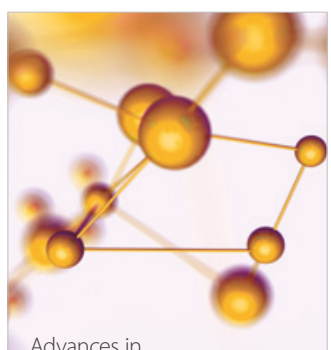

Physical Chemistry
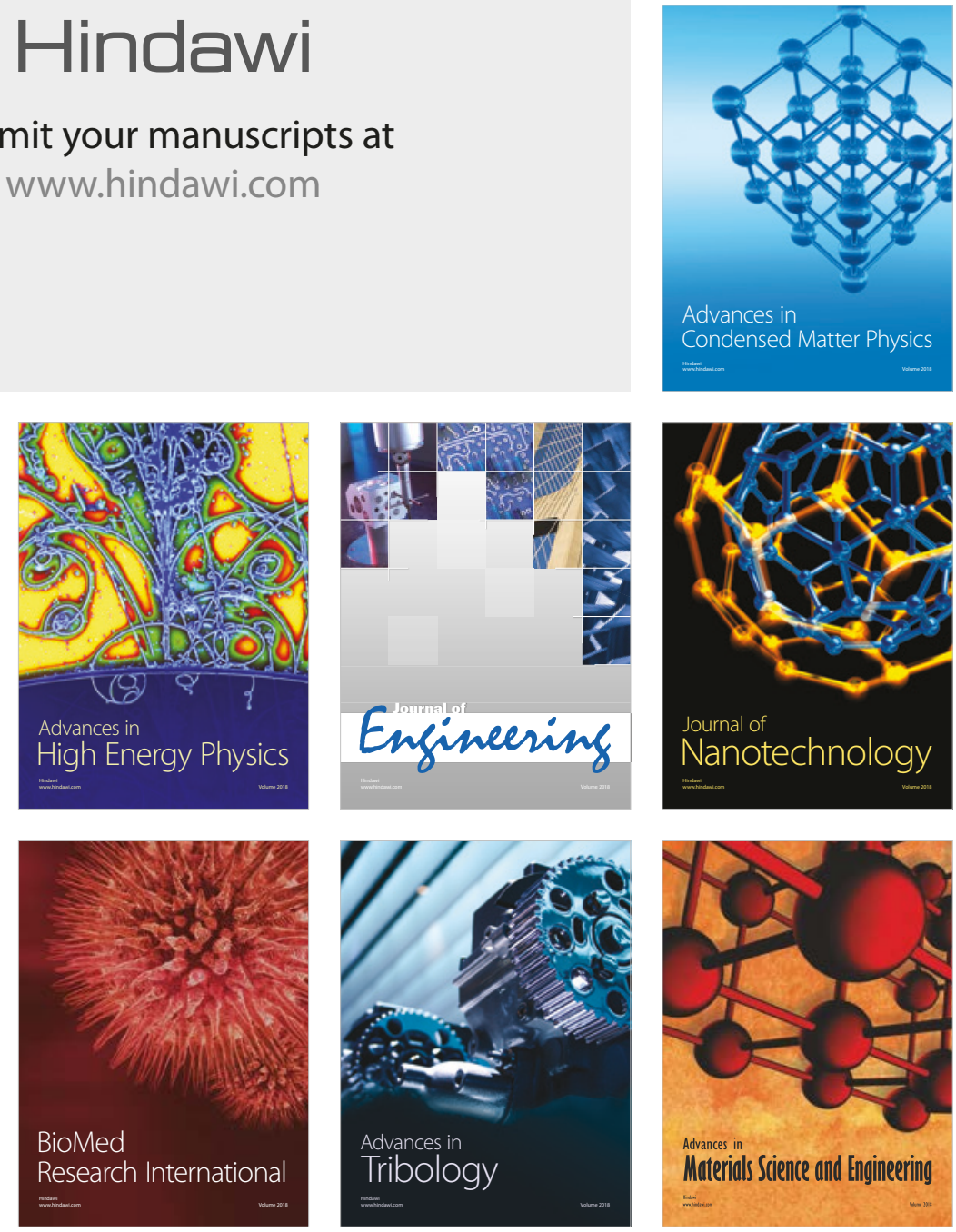